\title{
PERSEPSI DAN PARTISIPASI MASYARAKAT TERHADAP PENERAPAN PROGRAM KERJA BUMDES DWI AMERTHA SARI DI DESA JINENGDALEM
}

\author{
Eliska Pratiwi ${ }^{1}$, I Nyoman Sujana², lyus Akhmad Haris ${ }^{3}$ \\ Jurusan Pendidikan Ekonomi \\ Universitas Pendidikan Ganesha \\ Singaraja, Indonesia
}

\begin{abstract}
Abstrak
Penelitian ini bertujuan untuk mengetahui persepsi dan partisipasi masyarakat terhadap program kerja Badan Usaha Milik Desa (BUMDes) Dwi Amertha Sari Jinengdalem. Penelitian ini merupakan sebuah penelitian deskriptif dengan pendekatan kuantitatif. Populasi dalam penelitian ini berjumlah 4.651 orang. Teknik yang digunakan random sampling. Jumlah sampel sebanyak 98 orang Data dikumpulkan dengan metode wawancara dan kuesioner, analisis data yang digunakan adalah analisis deskriptif. Hasil penelitian menunjukkan bahwa : persepsi masyarakat terhadap program kerja BUMDes Dwi Amertha Sari Jinengdalem dikategorikan setuju hal ini dapat dilihat dari tiga dimensi yakni : dimensi pelaku persepsi ,objek yang dipersepsikan dan konteks dari situasi persepsi itu dilakukan jawaban responden dikategorikan Setuju, dan partisipasi masyarakat terhadap program kerja BUMDes Dwi Amertha Sari Jinengdalem dikategorikan tinggi hal ini dapat dilihat dari dua dimensi yakni dimensi perencanaan program kerjadan b) dimensi pelaksanaan program kerja jawaban responden dikategorikan Tinggi
\end{abstract}

Kata Kunci : Persepsi Mas yarakat, Partisipasi Masyarakat, dan Program Kerja BUMDes

Abstract

This study aims to determine public perceptions and community participation in the work program of BUMDes Dwi Amertha Sari Jinengdalem. This research is a descriptive study with a quantitative approach. The population in this study consists of 4,651 people. The technique used is random sampling. The number of samples was 98 people. Data were collected by interview method and questionnaire. Data analysis used was descriptive analysis. The results showed that: the public perception of the BUMDes Dwi Amertha Sari Jinengdalem program was categorized as Agree, it can be seen from three dimensions: the dimensions of the perceptions, objects perceived and the situation in which the perception was taken by the respondent's answer is categorized as Agree, and community participation in the BUMDes Dwi Amertha Sari Jinengdalem program is categorized as High this can be seen from two dimensions: program planning and program implementation are categorized as High

Keywords: Community Perception, Community Participation, and BUMDes Work Program 


\section{PENDAHULUAN}

Desa merupakan salah satu tempat yang potensial bagi pertumbuhan perekonomian yang berbasis kerakyatan. Di desa banyak potensi yang bisa dikembangkan, dan banyak sumber daya alam yang tersedia. Pemerintah menyadari akan potensi desa yang begitu besar, maka pemerintah menerbitkan sebuah kebijakan yakni Otonomi Daerah tujuannya agar daerah memanfaatkan dan mengembangkan wilayahnya terutama mengembangkan perekonomiannya. Salah satu aktivitas yang dilakukan adalah badan usaha milik desa.

Lembaga pengembangan ekonomi ini tidak lagi didirikan atas dasar intruksi pemerintah akan tetapi berangkat dari adanya potensi yang ada, sehingga jika dikelola dengan baik akan menggerakan roda perekonomian. Agar keberadaan lembaga pengembangan ekonomi ini tidak dikuasai pihak tertentu (pemilik modal besar), maka kepemilikan lembaga ini harus dikelola oleh desa dan dikontrol bersama-sama sehingga tujuan utama lembaga dalam pemberdayaan masyarakat dapat terwujudkan.

Salah satu kelembagaan sebagaimana dimaksud di atas adalah Badan Usaha MilikDesa (BUMDes). Badan usaha ini sesungguhnya telah diamanatkan di dalam UU No. 32 Tahun 2004 tentang Pemerintahan Daerah dan Peraturan Pemerintah (PP) nomor 71 Tahun 2005 Tentang Desa. Pendirian badan usaha ini harus disertai dengan penguatan kapasitas dan dukungan dari pemerintah (kebijakan) yang memfasilitasi dan melindungi usaha ini dari ancaman persaingan para pemodal besar.

BUMDes yang merupakan pilar kegiatan ekonomi di desa yang berfungsi sebagai lembaga sosial (social institution) dan komersial (commercial institution). BUMDes sebagai lembaga sosial berpihak kepada kepentingan masyarakat melalui kontribusinya dalam penyediaan pelayanan sosial. Sedangkan sebagai lembaga komersial bertujuan mencari keuntungan melalui penawaran sumber daya lokal (barang dan jasa) kepasar. Dalam menjalankan usahanya prinsip efisiensi dan efektifitas harus selalu ditekankan. BUMDes sebagai badan hukum, dibentuk berdasarkan tata perundang-undangan yang berlaku, dan sesuai dengan kesepakatan yang terbangun di masyarakat desa.

Persepsi merupakan suatu proses yang dimulai dari penglihatan hingga terbentuk tanggapan yang terjadi dalam diri individu sehingga individu sadar akan segala sesuatu dalam lingkungannya melalui indera-indera yang dimilikinya. Persepsi akan memberikan dampak yang baik maupun buruk terhadap suatu objek yang berbeda-beda, meskipun diberikan objek yang sama, akan tetapi persepsi seseorag akan berbeda-beda. Menurut Irwanto (2002), setelah individu melakukan interaksi dengan obyek-obyek yang di persepsikan maka hasil persepsi dapat dibagi menjadi dua yaitu, persepsi positif dan persepsi negatif.

Adapun menurut Walgito (2004:70) mengungkapkan bahwa "persepsi merupakan suatu proses pengorganisasian, penginterpretasian terhadap stimulus yang diterima oleh organisme atau individu sehingga menjadi sesuatu yang berarti, dan merupakan aktivitas yang integrated dalam diri individu". Respon sebagai akibat dari persepsi dapat diambil oleh individu dengan berbagai macam bentuk. Menurut Robbins (2002) terdapat 3 (tiga) faktor yang mempengaruhi terbentuknya persepsi. Ketiga faktor tersebut adalah pelaku persepsi, objek yang dipersepsikan, konteks dari situasi persepsi itu dilakukan.

Istilah partisipasi sering diartikan dalam kaitannya dengan pembangunan sebagai pembangunan masyarakat yang mandiri, perwakilan, mobilitas sosial, pembagian sosial yang merata terahadap hasil-hasil pembangunan, penetapan kelembagaan khusus, demokrasi politik dan sosial, reformasi sosial, atau bahkan yang disebut revolusi rakyat. Menurut Goldsmith dan Blustain dalam Winarto (2003) ada tiga alasan yang menyebabkan masyarakat tergerak untuk berpartisipasi. Pertama, partisipasi dilakukan melalui organisasi yang sudah dikenal atau yang sudah ada di tengah-tengah masyarakat yang bersangkutan. kedua partisipasi itu 
memberikan manfaat langsung kepada masyarakat yang bersangkutan, ketiga manfaat yang diperoleh melalui partisipasi itu dapat memenuhi kepentingan masyarakat setempat, dan keempat dalam proses partisipasi itu dijamin adanya kontrol yang dilakukan oleh masyarakat.

Dengan mengetahui persepsi dan partisipasi masyarakat terhadap program kerja BUMDesa, agar pelaksanaan program kerja dapat berjalan dengan baik.

Dalam pelakasanaan program kerja ini diharapkan persepsi dan partisipasinya masyarakat desa untuk dapat melaksanakan program ini. Berdasarkan latar belakang di atas maka penelitian ini bertujuan untuk mengetahui persepsi dan partisipasi masyarakat terhadap program kerja BUMDesa Dwi Amertha Sari Jinengdalem.

\section{METODE}

Penelitian ini merupakan sebuah penelitian deskriptif dengan pendekatan kuantitatif. Populasi yang digunakan adalah seluruh masyarakat desa Jinengdalem yang berjumlah 4651 orang. Teknik pengambilan sampel yang digunakan adalah random sampling. Jumlah sampel yang digunakansebanyak 98 orang Sumber data yang digunakan dalam penelitian ini adalah data primer dan data sekunder. Data primer dalam penelitian ini yaitu hasil kuesioner yang di isi oleh masyarakat desa. Data sekunder berupa data yang diperoleh dari dokumen atau catatan pihak BUMDesa mengenai data jumlah masyarakat desa Jinengdalem.

Dalam melakukan penelitian, peneliti menggunakan metode kuesioner.
Kuesioner digunakan untuk memperoleh data tentang persepsi dan partisipasi masyarakat terhadap program kerja BUMDes Dwi Amertha Sari Jinengdalem. Instrumen penelitian ini berupa kuisioner dan wawancara, kuisioner untuk memperoleh data mengenai persepsi persepsi dan partisipasi masyarakat terhadap program kerja BUMDes Dwi Amertha Sari Jinengdalem. Menurut Irianto (2004), untuk memperoleh skala interval persepsi dilakukan langkah-langkah sebagai berikut.

Pertama menentukan skor terendah dan skor tertinggi dari keseluruhan alternative jawaban.

Skor $_{\max }=$ nilai maksimal $\mathrm{x}$ jumlah
pertanyaan $\mathrm{x}$ jumlah responden

Skor $_{\min }=$ nilai minimal $\mathrm{x}$ jumlah pertanyaan $\mathrm{x}$ jumlah responden

Kedua menentukan interval persepsi dan partisipasi masyarakat terhadap program kerja BUMDes Dwi Amertha Sari Jinengdalem.

Interval $=\frac{\text { skor tertinggi-skor tenendah }}{\text { kategori }}$

(Irianto, 2004)

Dari langkah-langkah yang telah dijelaskan di atas maka menghasilkan kriteria persepsi sebagai berikut. Kriteria skor persepsi masyarakat terhadap program kerja BUMDes Dwi Amertha Sari Jinengdalem dimensi pelaku persepsi yang terdiri dari tiga indikator yaitu indikator sikap, indikator harapan, dan indikator motivasi, dan kriteria total dimensi pelaku persepsi dapat dilihat pada Tabel 1.

Tabel 1. Kriteria Total Skor Variabel Persepsi Masyarakat terhadap Program Kerja BUMDes Dwi Amertha Sari Jinengdalem dari Dimensi Pelaku Persepsi

\begin{tabular}{ll}
\hline Rentang skor & Kategori \\
\hline $4116-4.900$ & Sangat Setuju \\
\hline $3333-4115$ & Setuju \\
\hline $2549-3332$ & Kurang Setuju \\
\hline $1765-2548$ & Tidak Setuju \\
\hline
\end{tabular}


p-ISSN : $2599-1418$

Jurnal Pendidikan Ekonomi Undiksha

e-ISSN : 2599 - 1426

Volume 11 No. 1 Tahun 2019

$981-1764$

Sangat Tidak Setuju 
Kriteria skor persepsi masyarakat terhadap program kerja BUMDes Dwi Amertha Sari Jinengdalem dimensi objek yang dipersepsikan dengan indikator pelaksanaan program kerja dapat dilihat pada tabel 2 berikut ini.

Tabel 2. Kriteria Skor Variabel Persepsi Masyarakat terhadap Program Kerja BUMDes Dwi Amertha Sari Jinengdalem dari Indikator pelaksanaan program kerja BUMDes

\begin{tabular}{ll}
\hline Rentang skor & Kategori \\
\hline $823-980$ & Sangat Setuju \\
\hline $666-822$ & Setuju \\
\hline $509-665$ & Kurang Setuju \\
\hline $352-508$ & Tidak Setuju \\
\hline $195-351$ & Sangat Tidak Setuju \\
\hline
\end{tabular}

Kriteria skor persepsi masyarakat terhadap program kerja BUMDes Dwi Amertha Sari Jinengdalem dimensi konteks dari situasi dimana persepsi itu dilakukan yang terdiri dari dua indikator yaitu indikator fasilitas, dan indikator suasana dan kritera total dimensi konteks dari situasi dimana persepsi itu dilakukan dapat dilihat pada tabel 3 berikut ini.

Tabel 3. Kriteria Total Skor Variabel Persepsi Masyarakat terhadap Program Kerja BUMDes Dwi Amertha Sari Jinengdalem dari Dimensi Konteks dari Situasi di mana Persepsi itu dilakukan

\begin{tabular}{ll}
\hline Rentang skor & Kategori \\
\hline $2.058-2450$ & Sangat Setuju \\
\hline $1.666-2.057$ & Setuju \\
\hline $1.274-1.665$ & Kurang Setuju \\
\hline $882-1273$ & Tidak Setuju \\
\hline $711-881$ & Sangat Tidak Setuju \\
partisipasi masyarakat & dan kritera total dimensi perencanaan \\
kerja BUMDes Dwi & dan pelaksanaan dapat dilihat pada tabel 4 \\
Jinengdalem dimensi & berikut \\
dan pelaksanaan &
\end{tabular}

Tabel 4. Kriteria Total Skor Variabel Patisipasi Masyarakat terhadap Program Kerja BUMDes Dwi Amertha Sari Jinegdalem dari Indikator Perencanaan dan Pelaksanaan Program Kerja

\begin{tabular}{ll}
\hline Rentang skor & Kategori \\
\hline $2.058-2450$ & Sangat Tinggi \\
\hline $1.666-2.057$ & Tinggi \\
\hline $1.274-1.665$ & Cukup Tinggi \\
\hline $882-1273$ & Rendah \\
\hline $711-881$ & Sangat Rendah \\
\hline
\end{tabular}




\section{HASIL DAN PEMBAHASAN}

Hasil

Berdasarkan perhitungan yang dilakukan dengan perbandingan skala interval yang diperoleh, maka dapat diketahui tingkat persepsi masyarakat terhadap program kerja BUMDes dwi amertha sari jinengdalem ditinjau dari dimensi pelaku persepsi dan hasil presentase persepsi masyarakat terhadap program kerja BUMDes Dwi Amertha Sari Jinengdalem dapat dilihat pada

Tabel 5. Persentase Persepsi Masyarakat terhadap Program Kerja BUMDes Dwi Amertha Sari Jinengdalem

\begin{tabular}{|c|c|c|c|c|c|c|}
\hline \multirow[t]{2}{*}{ Dimensi } & \multirow[t]{2}{*}{ Indikator } & \multicolumn{5}{|c|}{ Persentase } \\
\hline & & SS & S & KS & TS & STS \\
\hline \multirow{3}{*}{$\begin{array}{l}\text { Pelaku } \\
\text { Persepsi }\end{array}$} & Sikap & $19,3 \%$ & $70,3 \%$ & $9,2 \%$ & $1,2 \%$ & 0 \\
\hline & Harapan & $29,7 \%$ & $62,5 \%$ & $6,2 \%$ & $1,7 \%$ & 0 \\
\hline & Motivasi & $38,4 \%$ & $51 \%$ & $9,2 \%$ & $0,7 \%$ & $0,7 \%$ \\
\hline \multicolumn{2}{|l|}{ Total } & $29,1 \%$ & $61,3 \%$ & $8,2 \%$ & $1,2 \%$ & $0,2 \%$ \\
\hline $\begin{array}{l}\text { Objek yang di } \\
\text { persepsikan }\end{array}$ & $\begin{array}{l}\text { Pelaksanaan } \\
\text { Program Kerja } \\
\text { BUMDesa }\end{array}$ & $24,2 \%$ & $70,4 \%$ & $8 \%$ & $0,5 \%$ & $2,2 \%$ \\
\hline \multicolumn{2}{|l|}{ Total } & $24,2 \%$ & $70,4 \%$ & $8 \%$ & $0,5 \%$ & $2,2 \%$ \\
\hline \multirow[t]{2}{*}{ Konteks } & Fasilitas & $35 \%$ & $51,4 \%$ & $11,9 \%$ & $1,7 \%$ & $0,3 \%$ \\
\hline & Suasana & $34,7 \%$ & $53,6 \%$ & $7,7 \%$ & $4,1 \%$ & 0 \\
\hline \multicolumn{2}{|l|}{ Total } & $34,85 \%$ & $52,5 \%$ & $9,8 \%$ & $2,9 \%$ & $0,15 \%$ \\
\hline \multicolumn{3}{|c|}{$\begin{array}{l}\text { Berdasarkan perhitungan yang } \\
\text { dilakukan dengan perbandingan skala } \\
\text { interval yang diperoleh, maka dapat } \\
\text { diketahui tingkat partisipasi masyarakat } \\
\text { terhadap program kerja BUMDes Dwi }\end{array}$} & $\begin{array}{l}\text { Ame } \\
\text { dime } \\
\text { prese } \\
\text { progr } \\
\text { Jinen }\end{array}$ & $\begin{array}{l}\text { Sari } \\
\text { pelaki } \\
\text { se partis } \\
\text { kerja B } \\
\text { lem da }\end{array}$ & $\begin{array}{l}\text { ngdalem } \\
\text { persepsi } \\
\text { si masya } \\
\text { Des Dwi } \\
\text { dilihat }\end{array}$ & $\begin{array}{l}\text { ditinjau dari } \\
\text { dan hasil } \\
\text { akat terhadap } \\
\text { Amertha Sari } \\
\text { ada tabel } 6 .\end{array}$ \\
\hline
\end{tabular}

Tabel 6. Hasil Analisis Data Persentase Partisipasi Masyarakat terhadap Program Kerja BUMDesa Dwi Amertha Sari Jinengdalem

\begin{tabular}{|c|c|c|c|c|c|c|}
\hline \multirow{2}{*}{ Dimensi } & \multirow{2}{*}{ Indikator } & \multicolumn{5}{|c|}{ Persentase } \\
\hline & & ST & $T$ & CT & $\mathrm{R}$ & SR \\
\hline Perncanaan & $\begin{array}{l}\text { Proses } \\
\text { perencanaan } \\
\text { program kerja } \\
\text { BUMDesa }\end{array}$ & $23,5 \%$ & $68,1 \%$ & $5,9 \%$ & $2,6 \%$ & $0 \%$ \\
\hline Total & & $23,5 \%$ & $68,1 \%$ & $5,9 \%$ & $2,6 \%$ & $0 \%$ \\
\hline Pelaksanaan & $\begin{array}{l}\text { Proses } \\
\text { pelaksanaan } \\
\text { program kerja } \\
\text { BUMDesa }\end{array}$ & $34,7 \%$ & $59,2 \%$ & $6,1 \%$ & $0 \%$ & $0 \%$ \\
\hline Total & & $34,7 \%$ & $59,2 \%$ & $6,1 \%$ & $0 \%$ & $0 \%$ \\
\hline $\begin{array}{r}\text { Pembahasar } \\
\text { Berdas } \\
\text { persepsi ma } \\
\text { kerja BUMDe }\end{array}$ & $\begin{array}{ll}\text { Kan } & \text { hasil } \\
\text { rakat } & \text { terhadap } \\
\text { adalah semua }\end{array}$ & $\begin{array}{l}\text { penelitian, } \\
\text { program } \\
\text { menjawab }\end{array}$ & $\begin{array}{l}\text { setuj } \\
\text { menc } \\
\text { progr } \\
\text { diliha }\end{array}$ & $\begin{array}{l}\text { Masyara } \\
\text { ang dar } \\
\text { kerja } \mathrm{E} \\
\text { ari hasi }\end{array}$ & $\begin{array}{l}\text { di des } \\
\text { ouka c } \\
\text { esa in } \\
\text { elitian }\end{array}$ & $\begin{array}{l}\text { neng } \\
\text { an ac } \\
\text { I ini } \\
\text { dipe }\end{array}$ \\
\hline
\end{tabular}


dari tiga dimensi yaitu pelaku persepsi, objek yang dipersepsikan, dan konteks dari situasi dimana persepsi itu dilakukan. Jawaban responden terhadap masingmasing indikator berbeda. Hal ini sesuai dengan pendapat philip kothler (2005), bahwa orang dapat memiliki persepsi yang berbeda-beda atas objek yang sama. Hasil penelitian menunjukkan bahwa persepsi masyarakat terhadap program kerja BUMDesa dimensi pelaku persepsi yang mencakup indikator sikap sebesar 1.646 berada pada skala interval 1.646 - 1.960 yang menunjukkan bahwa persespsi dikategorikan sangat setuju. Hal ini berarti masyarakat sangat setuju dengan program kerja BUMDesa mereka akan lebih mudah terbantu dari progran-program yang dilaksanakan BUMDesa. Sikap yang ditunjukan yakni menunjukkan tingkah laku positif seperti masyarakat dapat melakukan pembayaran rekening listrik dan air setiap bulannya, dan selalu mengikuti programprogram yang telah dibuat oleh BUMDesa. Indikator harapan sebesar 1.234 berada pada skala interval 1.000 - 1.234 yang menunjukkan bahwa persespsi dikategorikan setuju. Hal ini menunjukkan bahwa masyarakat berharap agar pelaksanaan program kerja BUMDesa dapat meningkatkan perekonomian desa. Indikator motivasi sebesar 1.252 berada pada skala interval 1.235 - 1.470 yang menunjukkan bahwa persespsi di kategorikan sangat setuju. Hal ini berarti masyarakat memiliki motivasi yang tinggi untuk dapat mengikuti penerapan program kerja BUMDesa agar nantinya dapat meningkatkan pendapatan di desa. Hasil total dimensi pelaku persepsi sebesar 4.132 berada pada skala 4.116 - 4.900 yang menunjukkan kategori sangat setuju.

$$
\text { Sedangkan hasil penelitian }
$$

menunjukkan bahwa persepsi masyarakat terhadap program kerja BUMDesa dimensi objek yang dipersepsikan dengan indikator penerapan program kerja BUMDesa sebesar 800 berada pada skala interval 666 - 822 yang menunjukkan bahwa persespsi dikategorikan sangat setuju. Hal ini berarti penerapan program kerja BUMDesa berjalan dengan baik.
Sedangkan hasil penelitian menunjukkan bahwa persepsi masyarakat terhadap program kerja BUMDesa dimensi konteks dari situasi dimana persepsi itu dilakukan yang mencakup indikator fasilitas sebesar 1.233 berada pada skala interval 1.000 - 1.234 yang menunjukkan bahwa persespsi dikategorikan setuju. Hal ini setuju bahwa masyarakat merasa senang berada di lingkungan kantor BUMDesa karena masyarakat dapat lebih mudah melakukan kegiatan yang termasuk program kerja yang dilakukan dan dapat terbantu dengan fasilitas yang disediakan. Indikator suasana sebesar 821 berada pada skala interval 666 - 822 yang menunjukkan bahwa persespsi dikategorikan setuju. Hal ini sangat setuju bahwa siswa merasa tenang dan kondusif berada dilingkungan kantor BUMDesa. Hasil total dimensi konteks dari situasi dimana persepsi itu dlakukan sebesar 2.054 berada pada skala interval 1666 2.057 yang menunjukkan kategori setuju.

Presentase tiga dimensi yakni pelaku persepsi jawaban responden Sangat Setuju (SS) 29,1\%, Setuju (S) 61,3\%, Kurang Setuju (KS) 8,2\%, Tidak Setuju (TS) $1,2 \%$, Sangat Tidak Setuju (STS) $0,2 \%$. Dimensi objek yang dipersepsikan jawaban responden Sangat Setuju (SS) 24,2\%, Setuju (S) 70,4\%, Kurang Setuju (KS) $8 \%$, Tidak Setuju (TS) 1,7\% Sangat Tidak Setuju (STS) 2,2\%. Dimensi konteks dari situasi dimana persepsi itu dilakukan jawaban responden Sangat Setuju (SS) $34,9 \%$, Setuju (S) $52,5 \%$, Kurang Setuju (KS) 9,8\%, Tidak Setuju (TS) 2,9\%, Sangat Tidak Setuju (STS) 0,15\%.

Berdasarkan hasil penelitian, partisipasi masyarakat terhadap program kerja BUMDesa adalah semua menjawab setuju. Masyarakat di desa Jinengdalem mendukung dan berpartisipasi dengan adanya program kerja BUMDesa ini. Hal ini dapat dilihat dari hasil penelitian yang diperoleh dari dua dimensi yaitu perencanaan dan pelaksanaan program kerja BUMDesa. Jawaban responden terhadap masing-masing indikator berbeda. Hasil penelitian menunjukkan bahwa partisipasi masyarakat terhadap program kerja BUMDesadilihat dari dimensi 
perencanaan program kerja BUMDesa sebesar 1.617 berada pada skala interval 1.332 - 1.645 yang menunjukkan bahwa partisipasi dikategorikan setuju. Hal ini berarti masyarakat setuju dengan adanya perencanaan program kerja BUMDesa mereka akan lebih mudah terbantu dari progran-program yang akan dilaksanakan BUMDesa.

Sedangkan hasil penelitian menunjukkan bahwa partisipasi masyarakat terhadap program kerja BUMDesa dilihat dari dimensi pelaksanaan program kerja BUMDesa sebesar 1.680 berada pada skala interval $1.646-1.960$ yang menunjukkan bahwa partisipasi dikategorikan sangat setuju. Hal ini berarti masyarakat sangat setuju dengan pelaksanaan program-program kerja BUMDesa mereka akan lebih mudah terbantu dari progran-program yang dilaksanakan BUMDesa. Sikap yang ditunjukkan yakni menunjukkan tingkah laku positif seperti masyarakat dapat melakukan pembayaran rekening listrik dan air setiap bulannya, dan selalu mengikuti programprogram yang telah dibuat oleh BUMDesa.

Presentase dua dimensi yakni perencanaan jawaban responden Sangat Tinggi (ST) 23,5\%, Tinggi (T) 68,1\%, Cukup Tinggi (CT) 5,9\%, Rendah (R) 2,6\%, Rendah Sekali (RS) 0\%. Dimensi pelaksanaan jawaban responden Sangat Tinggi (ST) 34,7\%, Tinggi (T) 59,2\%, Cukup Tinggi (CT) 6,1\%, Rendah (R) 0\% Sangat Rendah (RS) $0 \%$.

\section{SIMPULAN DAN SARAN Simpulan}

Hasil penelitian menunjukan bahwa,

Persepsi masyarakat terhadap proram kerja BUMDesa Dwi Amertha Sari Jinegdalem menunjukkan setuju. $\mathrm{Hal}$ itu dilihat dari hasil penelitian menunjukkan bahwa persepsi masyarakat terhadap program kerja BUMDesa Dwi Amertha Sari Jinegdalem dapat dilihat dari tiga dimensi yakni : 1) Pelaku Persepsi sebesar 4.132 berada pada skala interval 4.116 - 4.900 yang menunjukkan sangat baik sekali, 2) dimensi Objek yang Dipersepsikan dengan indikator pelaksanaan program kerja
BUMDesa sebesar 800 berada pada skala interval 666 - 2057 yang menunjukkan kategori sangat baik sekali, 3) dimensi Konteks dari Situasi di mana persepsi itu dilakukan sebesar 2.054 berada pada skala interval $1.666-2.057$ yang menunjukkan kategori sangat baik.

Partisipasi masyarakat terhadap proram kerja BUMDesa Dwi Amertha Sari Jinegdalem menunjukkan setuju. Hal itu dilihat dari hasil penelitian menunjukkan bahwa persepsi masyarakat terhadap proram kerja BUMDesa Dwi Amertha Sari Jinegdalem dapat dilihat dari dua dimensi yakni : 1) perencanaan program kerja sebesar 1.617 berada pada skala interval 1.332 - 1.645 yang menunjukkan kategori tinggi, dan 2) dimensi pelaksanaan program kerja sebesar 1.680 berada pada skala interval 1.646 - 1.960 yang menunjukkan kategori sangat tinggi.

\section{Saran}

Berdasarkan hasil simplan di atas, maka dapat diajukan saran sebagai berikut. Bagi peneliti yang lain

Peneliti yang selanjutnya yang tertarik untuk mengkaji aspek yang serupa mengenai persepsi dan partisipasi terhadap program kerja BUMDesa, diharapkan untuk mengembangkan penelitian ini dengan menggunkan populasi dan sampel yang lebih luas lagi. tujuan yang ingin dicapai.

Bagi badan usaha milik desa BUMDesa dwi amertha sari jinengdalem

Dalam pihak ini, pihak BUMDesa dapat megetahui persepsi dan partisipasi masyarakat terhadap evaluasi program kerja BUMDesa, bagi peneliti dihaapkan pihak BUMDesa dapat meningkatkan kualitas dan kuantitas program kerja yang telah dilaksanakan.

\section{DAFTAR PUSTAKA}

Adi, Isbandi Rukminto. 2007. Perencanaan partisipatoris berbasis aset komunitas: dari pemikiran menuju penerapan. Depok: FISIP UI. Press.

Arikunto, Suharsimi. 2006. Prosedur Penelitian Suatu Pendekatan Praktik, 
Edisi Revisi VI. Jakarta: PT. Rineka Cipta.

Arikunto, Suharsimi. 2010. Prosedur Penelitian, Suatu Pendekatan Praktik. Jakarta: PT Rineka Cipta.

Departemen Pendidikan Nasional Pusat Kajian Dinamika Sistem Pembangunan (PKDSP). 2007. Buku Panduan Pendirian dan Pengelolaan Badan Usaha Milik Desa (BUMDes). Jakarta: Fakultas Ekonomi Universitas Brawijaya

Ikhsan, Arfan dan Muhammad Ishak. 2008. Akuntansi Keperilakuan. Jakarta: Salemba Empat

Irianto, Agus. 2004. Statistik Konsep Dasar dan Aplikasinya. Jakarta: Prenada Media.

Irwanto. 2002. Psikologi Umum, (Buku PANDUAN mahasiswa). Jakarta: PT. Prehallindo.

Kotler Philip. 2005, Manajemen Pemasaran, Jilid 1, PT. Indeks Kelompok Gramedia, Jakarta

Lugiarti E. 2004. Partisipasi Masyarakat Dalam Proses Pembangunan. Khanata. Jakarta.

Robbins SP, Dan Judge. 2002. Perilaku Organisasi. Jakarta: Salemba Empat.

Walgito, Bimo. 2004. Pengantar Psikologi Umum. Yogyakarta: Andi

Winarto, H. 2003. Partisipasi Masyarakat Dalam Kegiatan Agroforestry. [Tesis]. Program Pascasarjana Institut Pertanian Bogor. 